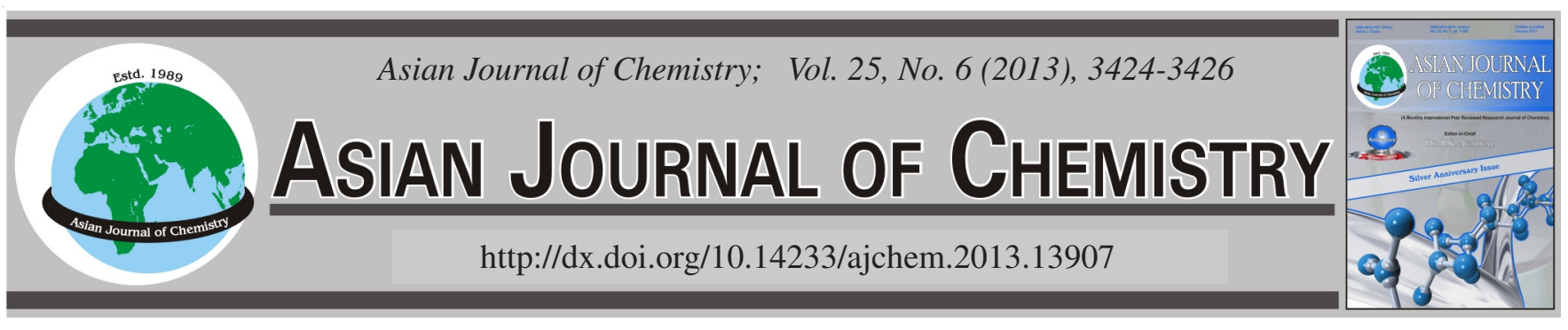

\title{
Study of the Content of Anions in the Pathologic Aqueous Humor by Ionic Capillary Electrophoresis
}

\author{
Momar Ndiaye ${ }^{1, *}$, El Hadj Amadou Ba ${ }^{2}$ and Abdoulaye Diop ${ }^{1}$
}

${ }^{1}$ Department of Chemistry, Faculty of Science and Technology, Cheikh Anta Diop University, Dakar, Senegal

${ }^{2}$ Faculty of Medicine, Pharmaceutical and Odonto-Stomatology, Cheikh Anta Diop University, Dakar, Senegal

*Corresponding author: Tel: +221 776407660; E-mail: momndiaye@ hotmail.com

(Received: 14 April 2012;

Accepted: 24 December 2012)

AJC-12604

\begin{abstract}
In this work, the content of certain anions of cataract affected patients has been determined. The aqueous humor was sampled with a sterile insulin syringe out of an inspiration puncture, at the ophthalmological clinic of Aristide Le Dantec Hospital. The measurements were taken by ionic capillary electrophoresis, which is a sensitive and specific technique of modern analysis. The detection limits for the electrolytes range from 20-84 ppb. The results of the measurements showed the presence of chloride ions (maxima $141.62 \mathrm{mmol} / \mathrm{L}$ ), nitrate ions (maxima $2.29 \mathrm{mmol} / \mathrm{L}$ ) and hydrogen phosphate ions (maxima $0.93 \mathrm{mmol} / \mathrm{L}$ ). Sulfate, chlorate and fluoride ions were also detected, but at a state of traces. The histograms of the Gauss curve made it possible to determine the reference values for the chloride and nitrate ions which present a normal distribution. Concerning the hydrogen phosphate, the average was considered to be a reference value. Besides, the comparison of results with the physiological data of the normal aqueous humor and the plasma shows the role of these ions in the genesis of the crystalline opacification.
\end{abstract}

Key Words: Electrolytes, Aqueous humor, Ionic capillary electrophoresis, Opacification, Crystalline.

\section{INTRODUCTION}

Electrophoresis started in 1892 with the works of Linder and Picton ${ }^{1}$. This technique was reserved for the analysis of colloidal particles, micelles and macromolecules. Important technological innovations have been introduced during the last 30 years owing to the benefits of chromatography liquid. Among the methods developed the best known is ionic capillary electrophoresis ${ }^{2,3}$. The technique uses a very small diameter silica glass capillary tube and makes it possible to separate ionized or ionizable species according to the difference of their migration in an electric field. Nowadays, several detectors (indirect-UV absorption, fluorescence, conductivity) can be placed after the capillary to visualize the solutes with a sensitivity that can reach $0.1 \mathrm{ppm}$. The method is commonly used in the pharmaceutical ${ }^{4}$, medical ${ }^{5}$, bio analytical ${ }^{4,6,7}$, agroalimentary ${ }^{4,8}$, environmental ${ }^{5}$ and industrial fields ${ }^{9,10}$.

In this study, this analytical method has been used to measure the anions contained in the aqueous humor of cataract affected patients. The electrolytes have been analyzed with a capillary electrophoresis equipped with an indirect-UV detector.

\section{EXPERIMENTAL}

Origin of the samples: The sampling was taken at the ophthalmological clinic of Aristide Le Dantec Hospital
(Dakar), on a sample of 40 cataract affected patients. This health service accommodates patients coming from various origins especially from Senegal but also from the neighboring countries.

The aqueous humor was extracted by aspiration puncture after washing the cornea and then performing a pre-incision with a blade. The patients' ages range from 33-80.

The experimental device used consisted of a UV detection electrophoresis capillary CIA WATERS ${ }^{\circledR}$ system, a data acquisition and treatment station and a computer equipped with MILLENIUM $2010^{\circledR}$ software.

The capillary electrophoresis is an analytical method based on the separation of the constituents of a sample. Then ionized species are determined according to their mobility under the effect of an electric field ${ }^{11}$.

The capillary has its two extremities extended in two different compartments, containing an electrolyte and a highvoltage anode. The power difference applied can reach $38 \mathrm{KV}$ for a necessary period. A detector placed on the path of the capillary makes it possible to identify the ion to analyze.

As for the content of anions, the injection is given from the cathodic side providing thus a negative supply.

Preparation of the samples and standards: The products used consist of a solution of $4 \mathrm{Mm}$ sodium chromate tetrahydrate, 
a $0.5 \mathrm{Mm}$ solution of OFM-OH, a boric acid solution, a standards solution especially made and commercialized by STANDAL and a solution of acetone for the cleaning of the electrodes.

The applied standards are useful to setting up standardization lines. The contents of anions are determined from these curves, by comparing the surfaces of the peaks to those of the standards. The normal solutions consist of precise quantities of each element to analyze. The ranges are generally between 0.1-150 ppm in electro-migrative mode of injection.

As part of our study, the ranges of prepared standards consist of an average combination of anions (Table-1).

\begin{tabular}{ccc}
\multicolumn{3}{c}{ TABLE-1 } \\
& RANGES OF USED STANDARDS \\
\hline Anion & Range 1 (mmol/L) & Range 2 (mmol/L) \\
\hline $\mathrm{Cl}^{-}$ & 1.40 & 0.70 \\
$\mathrm{NO}_{3}^{-}$ & 0.80 & 0.40 \\
$\mathrm{SO}_{4}^{2-}$ & 0.50 & 0.25 \\
$\mathrm{ClO}_{3}^{-}$ & 0.60 & 0.30 \\
$\mathrm{~F}$ & 1.30 & 0.65 \\
$\mathrm{HPO}_{4}^{2-}$ & 0.26 & 0.13 \\
\hline
\end{tabular}

The solution of chromate/OFM-OH used as electrolyte has been obtained by mixing in a $100 \mathrm{~mL}$ phial, a $4.5 \mathrm{~mL}$ volume of a solution of $\mathrm{Na}_{2} \mathrm{CrO}_{4}$ to a $0.1 \mathrm{M}, 2.5 \mathrm{~mL}$ of OFM-OH (osmotic flow modifier), $50 \mathrm{~mL}$ ultra pure water and $1 \mathrm{~mL}$ boric acid.

This has been completed to $100 \mathrm{~mL}$ with ultra pure water to obtain a solution of chromate/OFM-OH of $\mathrm{pH}$ equal to 8 .

\section{RESULTS AND DISCUSSION}

In this study, we have worked with a capillary electrophoresis equipped with an indirect-UV detector to visualize the elements as they come out of the capillary tube. The problem faced with is to have a mobile phase or electrolyte which absorbs at $254 \mathrm{~nm}$, wavelength of the mercury lamp used. The solution of chromate/OFM-OH makes it possible to analyze a standard combination of inorganic anions in $4 \mathrm{~min}$ (Fig. 1).

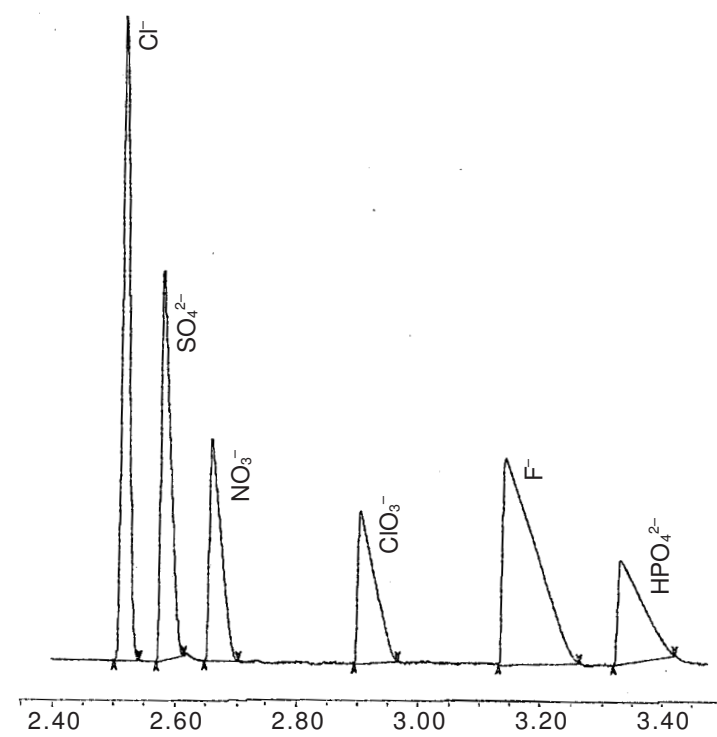

Fig. 1. Electrophoretogram of a standard combination of major anions
The results obtained by the standardization curve method reveal the presence of chloride (minima $108.22 \mathrm{mmol} / \mathrm{L}$, maxima $141.62 \mathrm{mmol} / \mathrm{L}$ ), nitrate (maxima $2.29 \mathrm{mmol} / \mathrm{L}$ ) and hydrogen phosphate (maxima $0.93 \mathrm{mmol} / \mathrm{L}$ ) elements.

However, contents of sulfate, chlorate and fluoride ions are identified in some samples. The presence of fluorides would be linked to the geographical origin of the patients. In effect, studies made by Sakho ${ }^{12}$, on the composition of water supply in Senegal, have shown high concentrations of fluoride ions (0.16-0.21 mmol/L) in the districts of Diourbel and Kaolack, in relation to the established standards by the World Health Organization $(0.03 \mathrm{mmol} / \mathrm{L})$.

When they are in high concentration, the chloride ions go through the blood and are then found in the aqueous humor.

Besides, the comparison of the results to the physiological data of the aqueous humor and the serum has raised questions about the role of these ions in the genesis of the opacification of the crystalline ${ }^{13}$.

The limits of the detection of the elements are compiled in Table-2 (Table-2).

\begin{tabular}{cccc}
\multicolumn{5}{c}{ TABLE-2 } \\
LIMITS OF DETECTION OF THE ELEMENTS \\
\hline Elements & LOD $(\mathrm{mmol} / \mathrm{L})$ & Elements & LOD $(\mathrm{mmol} / \mathrm{L})$ \\
\hline $\mathrm{Cl}^{-}$ & 0.0046 & $\mathrm{ClO}_{3}^{-}$ & 0.1 \\
$\mathrm{SO}_{4}{ }^{2-}$ & 0.032 & $\mathrm{~F}^{-}$ & 0.020 \\
$\mathrm{NO}_{3}^{-}$ & 0.084 & $\mathrm{HPO}_{4}{ }^{-2}$ & 0.041 \\
\hline
\end{tabular}

Determination of reference values: The results of a chemical analysis always go together with errors ${ }^{14}$.

Random or indeterminate errors appear when the maximal sensitivity of a measurement system is reached. They are caused by many incontrollable or measurable parameters. The individual detection of these errors is practically impossible because of their small size. Yet, their cumulative effect is at the root of the random distribution of the data of a series of measurements around the average. With the help of statistic treatment of these data, it is possible to make the judgment passed on their quality more acute and in this way to set up reference values ${ }^{15,16}$.

We have used the properties of the Gauss curve (normal distribution) to get rid of these aberrant values. The method consists in having a symmetric distribution around the average value. The histogram, so drawn, provides values around which all the other values split symmetrically (Figs. 2 and 3).

These data will be considered as reference values. As far as the hydrogen phosphate ion is concerned, the measurement results have revealed a high dispersion of values. The histogram obtained does not follow a Gaussian distribution, the average value is considered to be a reference value (Table-3).

The typical-variance characterizes the dispersion of values on both sides of the average. The higher the typical-variance, the larger the dispersion.

Besides, the comparison of the results to the physiologic composition of the normal aqueous humor and the plasma (Table-4) show the presence of new elements, which have not been pointed out in literature yet. In effect, the aqueous humor resulting from the ultra filtration, the diffusion and secretion of the non pigmented epithelium of the eyelash body shed in 


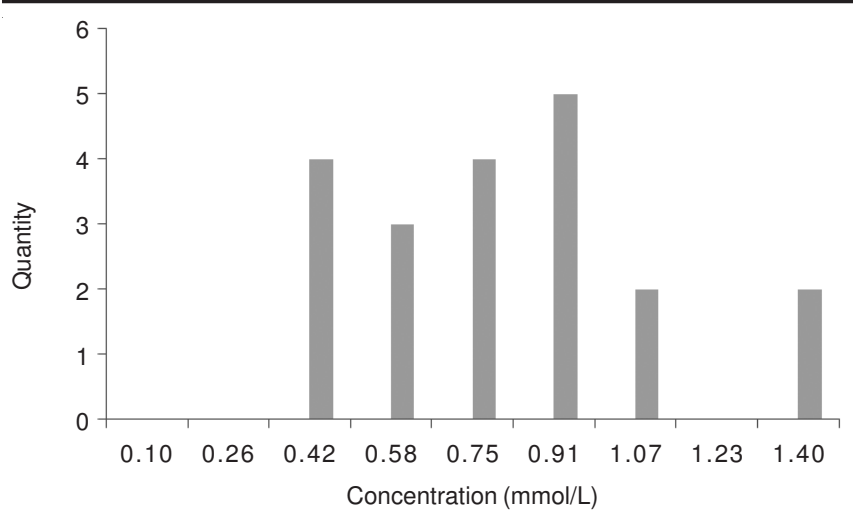

Fig. 2. Histogram of nitrates

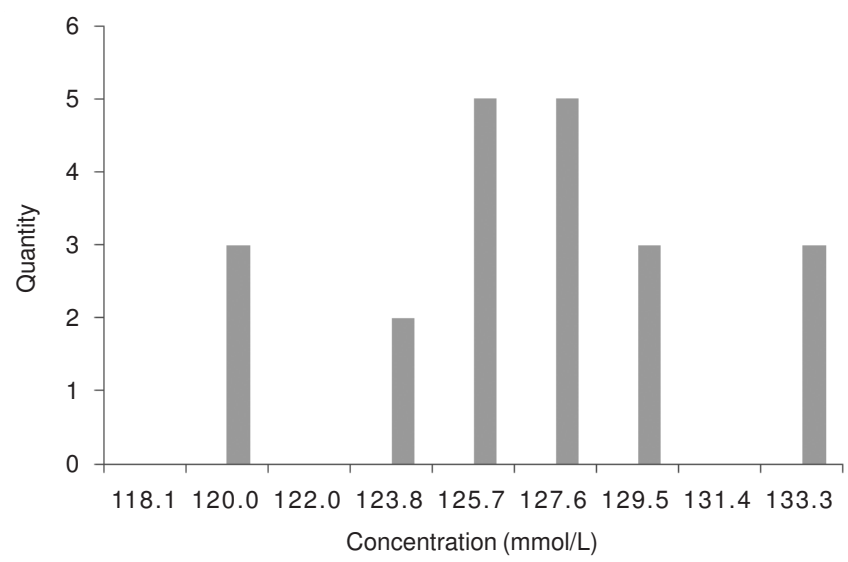

Fig. 3. Histogram of chlorides

\begin{tabular}{cc} 
TABLE-3 \\
REFERENCE VALUES (R.V.) OF \\
THE ELECTROLYTES, IN mmol/L \\
\hline Element & R.V. \\
\hline $\mathrm{Cl}^{-}$ & $125.70 \pm 3.80$ \\
$\mathrm{NO}_{3}^{-}$ & $0.91 \pm 0.32$ \\
$\mathrm{HPO}_{4}^{2-}$ & $0.47 \pm 0.19$ \\
\hline
\end{tabular}

\begin{tabular}{ccc}
\multicolumn{4}{c}{ TABLE-4 } \\
COMPOSITION OF THE AQUEOUS HUMOR AND THE PLASMA \\
\hline Elements & Aqueous humor (mmol/L) & Plasma (mmol/L) \\
\hline $\mathrm{Cl}^{-}$ & 131 & 103 \\
$\mathrm{HCO}_{3}^{-}$ & 22 & 26 \\
$\mathrm{H}_{2} \mathrm{PO}_{4}^{-}$ & 0.6 & 1.1 \\
\hline
\end{tabular}

the posterior chamber of the eye ${ }^{17}$. Before its passage through the pupillary opening between the posterior plan of the iris and the anterior capsule of the crystalline, the composition of the aqueous humor undergoes some modifications. Therefore, we notice an excess in the content of chloride and the presence of new substances. These elements which change the composition of the aqueous humor can be the cause of the opacification of the crystalline.

\section{Conclusion}

In this study, we have determined the contents of certain anions of cataract affected patients. The analysis has been achieved by means of ionic capillary electrophoresis a specific and very sensitive modern method. It made it possible to detect major electrolytes and some trace elements, which have not yet been detected. The presence of these ions, in addition to their content, seems to play a role in the opacification of the crystalline. This has been confirmed by a comparison of the results found in the physiological data of the aqueous humor and the plasma. Thus, a therapeutic possibility alternative to the surgical operation is opening. It constitutes nowadays the unique means to stop this plague. In order to better understand the mechanism linked to this opacification, it would be interesting to measure out, later on, the cations present in the aqueous humor of both affected and healthy subjects.

\section{ACKNOWLEDGEMENTS}

The authors thank the Chemistry Laboratory of the Development Research Institute (DIR) of Hann, for its collaboration.

\section{REFERENCES}

1. Encyclopaedia Universalis, 5, pp. 131-134 (1993).

2. J.P. Romano and J. Krol, J. Chromatogr. A, 640, 403 (1993).

3. D. Heiger and R. Weinberger, Hewlett-Packard Application Note, 125963-1138E (1994).

4. F. Rouessac, Analyse Chimique: Méthodes et Techniques Instrumentales Modernes, Ed. Masson (1992).

5. I.K. Reedy and M.G. Ganesan, Technomic Publishing Co., Inc, Lancaster, pp. 3-29 (1996).

6. Y. Jacques and P. Buri, Médecine et hygiène, Geneva, pp. 47-78 (1998).

7. S. Campagna, P.C. Molle and J.L. Gaillard, Biochim. Biophys. Acta, 1513, 217 (2001).

8. L. Miclo, E. Perrin, A. Driou, V. Papadopoulos, N. Boujrad, R. Vanderesse, J.F. Boudier, D. Desor and G.L. Gaillard, FASEB J., 15, 1780 (2001).

9. F. Cazier, M.N. Duval, H.C. Dubourguier and E. Degans, International Symposium, Oostende, Belgium, 21-24 April (1997).

10. M. Mazzuca, H. Ghandour, F. Cazier, V. Nollet, O. Duveau, J.M. Casquin, J. Houde, G. Zasina and J.C. Dechaux, Validation d'un Système Mobile D'analyse D'effluents Gazeux Industriels 11th World Clean Air \& Environment Congress, Durban, South Africa, 18 September (1998).

11. P. Jandik and G. Bonn, Capillary Electrophoresis of Small Molecules and Ions, Ed. VCH, New York (1993).

12. I. Sakho, DEA Chimie Physique, Université Cheikh Anta DIOP Dakar, Sénégal, p. 1997.

13. M. Ndiaye, A. Diop, El. Ba, F. Rastagar and S. Michel, Dakar Méd., 51, 33 (2006).

14. D.A. Skoog, D.M. West and F.J. Holler, Analytical Chemistry, Saunders College publishing, edn. 7, 00 (1997).

15. D.C. Harris, Quantitative Chemical Analysis, edn. 5 (1998).

16. M. Feinberg, Validation des méthodes d'analyses. Ed. Masson (1996).

17. C. Schnyder and A. Mermoud, Glaucome. Ed. Masson (2005). 